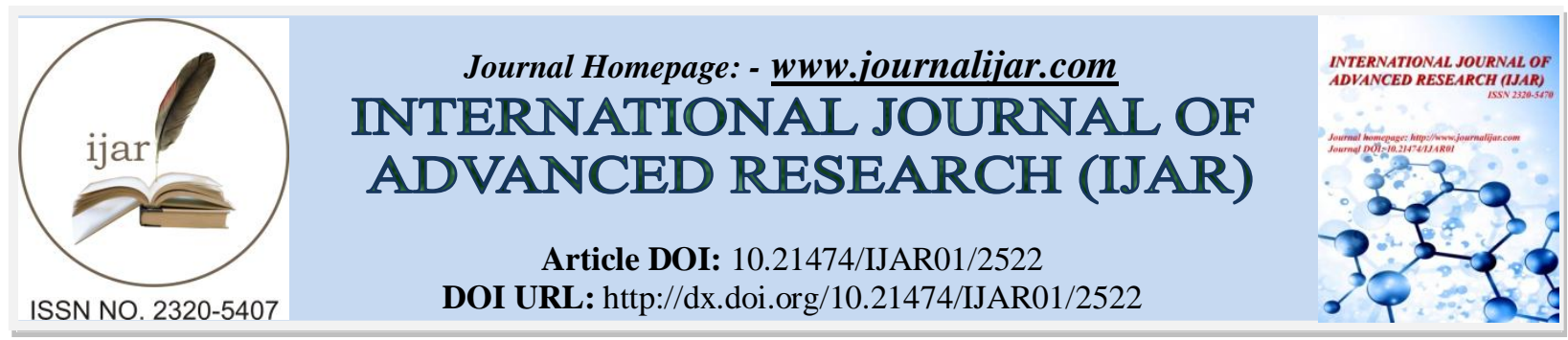

RESEARCH ARTICLE

\title{
INVASIVE SOLID PAPILLARY CARCINOMA BREAST-A RARE CASE REPORT.
}

\section{Dr. Amreen Brown ${ }^{1}$, "Dr. Parul Gupta ${ }^{2}$, Dr.Shruti Singh ${ }^{1}$, Dr. Nirupma Lal ${ }^{3}$, Dr. A.N. Srivastava ${ }^{4}$ and Dr. Osman Musa ${ }^{5}$.}

1. Junior Resident, Department of Pathology, Era's Lucknow Medical College \& Hospital, Lucknow, U.P. India.

2. Associate Professor, Department of Pathology, Era's Lucknow Medical College \& Hospital, Lucknow, U.P. India.

3. Professor, Department of Pathology, Era's Lucknow Medical College \& Hospital, Lucknow, U.P. India.

4. Professor, Department of Pathology, Era's Lucknow Medical College \& Hospital, Lucknow, U.P. India.

5. Professor and Head, Department of Surgery, Era's Lucknow Medical College \& Hospital, Lucknow, U.P. India.

\section{Manuscript Info}

Manuscript History

Received: 25 October 2016

Final Accepted: 23 November 2016

Published: December 2016

\section{Abstract}

Papillary lesions of the breast are a complex group ranging from benign to malignant. Invasive Papillary Breast Carcinomas are rare and account for approximately $0.5 \%$ of all invasive breast carcinomas. Here we report a case of 35 year old female who presented with a mass in the left breast Routine hematological investigations were within normal limits and USG revealed ill defined SOL .Grossly a well circumscribed grey-white tumor with few peripheral lobulations measuring $8 \times 10 \mathrm{~cm}$ was seen.Tumor appears to be reaching upto skin anteriorly and also reaching upto base posteriorly. Microscopically tumor is composed of large variable sized ducts completely filled by a solid proliferation of malignant cells. The rounded tumor nests are well circumscribed and multinodular.At periphery tumor shows infiltrative small nests of malignant cells, with surrounding desmoplastic stroma. Papillary carcinomas are mostly cystic. Solid lesions though occur less may be carcinomas with exclusive papillary morphology.They have a tendency to manifest as large masses which are related to the common presence of the bulky cystic components. Hence, the size of the invasive element is often small. For the cases showing invasion, prognosis depends on the invasive component.however cases without invasion show a better prognosis.

Copy Right, IJAR, 2016,. All rights reserved.

\section{Introduction:-}

Papillary lesions of the breast represents a complex group ranging from benign to malignant. Papillary carcinomas constitute $1-2 \%$ of breast cancers in women. Solid Papillary Carcinoma is an uncommon lesion that affects primarily elderly women .Mean age is 72 years and occasionally patients younger than 50years are affected(1,2).About $95 \%$ cases are unilateral. Majority arise in central area of the breast $(1,3)$. If the epithelium has features diagnostic of intraductal carcinomas, it is classified as papillary carcinoma in situ. If a cystic component is present it is called intracystic papillary carcinoma else called solid papillary carcinoma(4). Solid lesions are more invasive. Invasive Papillary Breast Carcinomas are rare and represent approximately $0.5 \%$ of invasive breast carcinomas(5). Invasive component mostly manifests as mucinous or neuroendocrine though other types may also be observed.

Corresponding Author:- Parul Gupta.

Address:- Associate Professor, Department of Pathology, Era’s Lucknow Medical College \& Hospital, 1301 
CASE HISTORY- A 35 year old female presented to the surgery OPD with a mass in the left breast. It had a duration of 7 months and increased in size since 3 months. No history of bloody nipple discharge present.On examination a bosselated mass felt in the inner and upper quadrant with retracted and inverted nipple.There is no significant family history present.

INVESTIGATION- Routine hematological investigations were within normal limits. USG revealed ill defined SOL with areas of micro-calcification and necrosis with increased internal vascularity in left breast suggestive of neoplastic pathology. Modified radical mastectomy with axillary dissection done.

Grossly the mastectomy specimen measuring $20 \times 14 \times 8 \mathrm{~cm}$ with attached skin eclipse measuring $17 \times 15 \mathrm{~cm}$ and attached axillary tail. Skin bears nipple and areola with retracted, inverted nipple.Cut surface shows well circumscribed grey-white tumor with few peripheral lobulations measuring $8 \times 10 \mathrm{~cm}$.Tumor appears to be reaching upto skin anteriorly and also reaching upto base posteriorly. Tumor is $1.5 \mathrm{~cm}$ from superior margin and also appears to be reaching to inferior margin. It also appears to be present on the inner medial aspect of breast.Cut surface of axillary tail shows grey brown areas. One of the peripheral areas show cystic area measuring $4 \times 4 \mathrm{~cm}$ filled with mucin.

Microscopically tumor is composed of large variable sized ducts completely filled by a solid proliferation of malignant cells. The rounded tumor nests are well circumscribed and multinodular. There is presence of delicate network of fibrovascular stroma distributed in an arborising pattern throughout the compact sheets of malignant cells. Tumor cells have high nucleo-cytoplasmic ratio, hyperchromatic, pleomorphic nucleus, clumped chromatin, prominent nucleoli and moderate amount of amphophilic cytoplasm. At periphery tumor shows infiltrative small nests of malignant cells, with surrounding desmoplastic stroma.Nuclear palisading around stromal core and psuedorossetting around capillaries present. Foci of large area shows necrosis. Foci of luminal mucin surrounded by similar tumor cells also seen.

Due to the frank nature of the invasion seen, the immunohistochemical markers for the identification of the myoepithelial cells were not considered as necessary. A diagnosis of an invasive solid papillary carcinoma of the breast was made. Axillary dissections yielded six lymph nodes which were negative for metastatic deposits.

DIFFERENTIAL DIAGNOSIS- Invasive micropapillary carcinoma, Florid ductal hyperplasia, lobular neoplasia, intracystic papillary carcinoma (IPC), and ordinary low-nuclear-grade ductal carcinoma in situ can be kept as a differential.

TREATMENT-Complete excision of the lesion,total or partial mastectomy is the treatment of choice for SPC. Data is not available to evaluate the role of sentinel lymph node biopsy in $\operatorname{SPC}(14,15)$.

\section{Discussion:-}

Papillary Carcinomas are usually present in the postmenopausal women.the mean age being between 63-67 years.In our case the patient is 35 year old women .Papillary Carcinomas are mostly discriminated as benign or malignant on the presence or absence of the myoepithelial component. Many authors have shown that solid papillary carcinomas lack myoepithelial cells at their periphery so the concept that solid papillary carcinomas are in situ tumors has been challenged. It remains a matter of controversy $(6,7,8)$.Malignant tumors are characterised by a frond-like growth pattern on a fibrovascular core lacking a myoepithelial layer.Pathologically four patterns exist- cribriform,compact columnar epithelial,stratified spindle cell and transitional.Combinations of these patterns may also be seen. Approximately $50 \%$ of papillary carcinomas arise in the retro-areolar or sub-areolar region of the breast.

Foote and Stewart observed that in some areas of the papillary carcinoma the cellular proliferation becomes dense and basic papillary properties become overgrown. Such tumors are classified as Solid Papillary Carcinomas (SPCs). The SPC cases are divided into three groups:1) SPC only (32.7\%),2) SPC with extravasated mucin (8.6\%), and 3) SPC with invasive components (58.7\%), which may be further devided like- A) Neuroendocrine-like (29.5\%),B) Colloid (23.5\%),C) Ductal not otherwise specified (14.5\%),D) Lobular (3\%), E)Tubular (3\%),F) Mixed (26.5\%)(9). Papillary carcinomas are mostly cystic. Solid lesions though occur less may be carcinomas with exclusive papillary morphology.They have a tendency to manifest as large masses which are related to the common presence of the bulky cystic components. Hence, the size of the invasive element is often small. 
Papillary carcinomas of breast are ER and progesterone receptor positive.They are Her2Neu negative $(10,11,12)$.Markers for myoepithelial cell layer for invasion assessment are Smooth muscle actin, p63, CD10, S-100, calponin and maspin. Smooth muscle myosin heavy chain and p63 are more specific $(12,13)$.

On mammography Invasive papillary carcinoma is a round, oval or lobulated mass .Margins are circumbscribed but may be obscured or indistinct. Accompaying microcalcifications or a dilated ductal pattern may be present.

Ultrasonographic evaluation of invasive papillary carcinomas reveal a hypoechoic and solid mass,commonly accompanied with posterior acoustic enhancement.Complex cystic and solid masses may be evident.

Invasive papillary carcinomas are infiltrating breast carcinomas with exclusive papillary morphology and should be distinguished from the other malignant papillary lesions. They should not be confused with invasive micropapillary carcinoma, which is a separate entity. Invasive papillary carcinoma, morphologically lacks true fibrovascular cores, and is characterised by neoplastic cells arranged in solid nests or tubules surrounded by clear spaces.

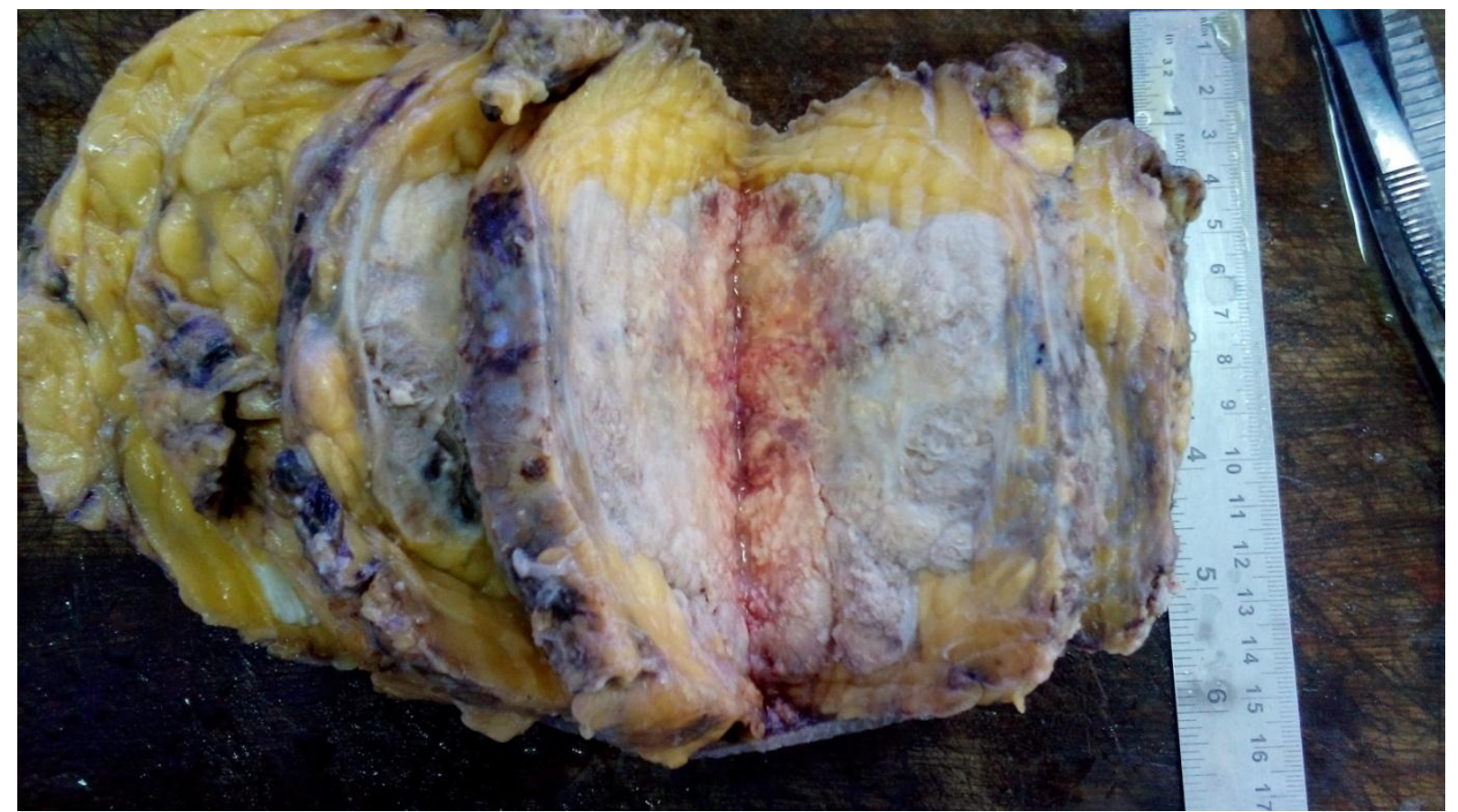

Fig.1:- Gross image showing well circumscribed grey white growth measuring 9x4cm. 


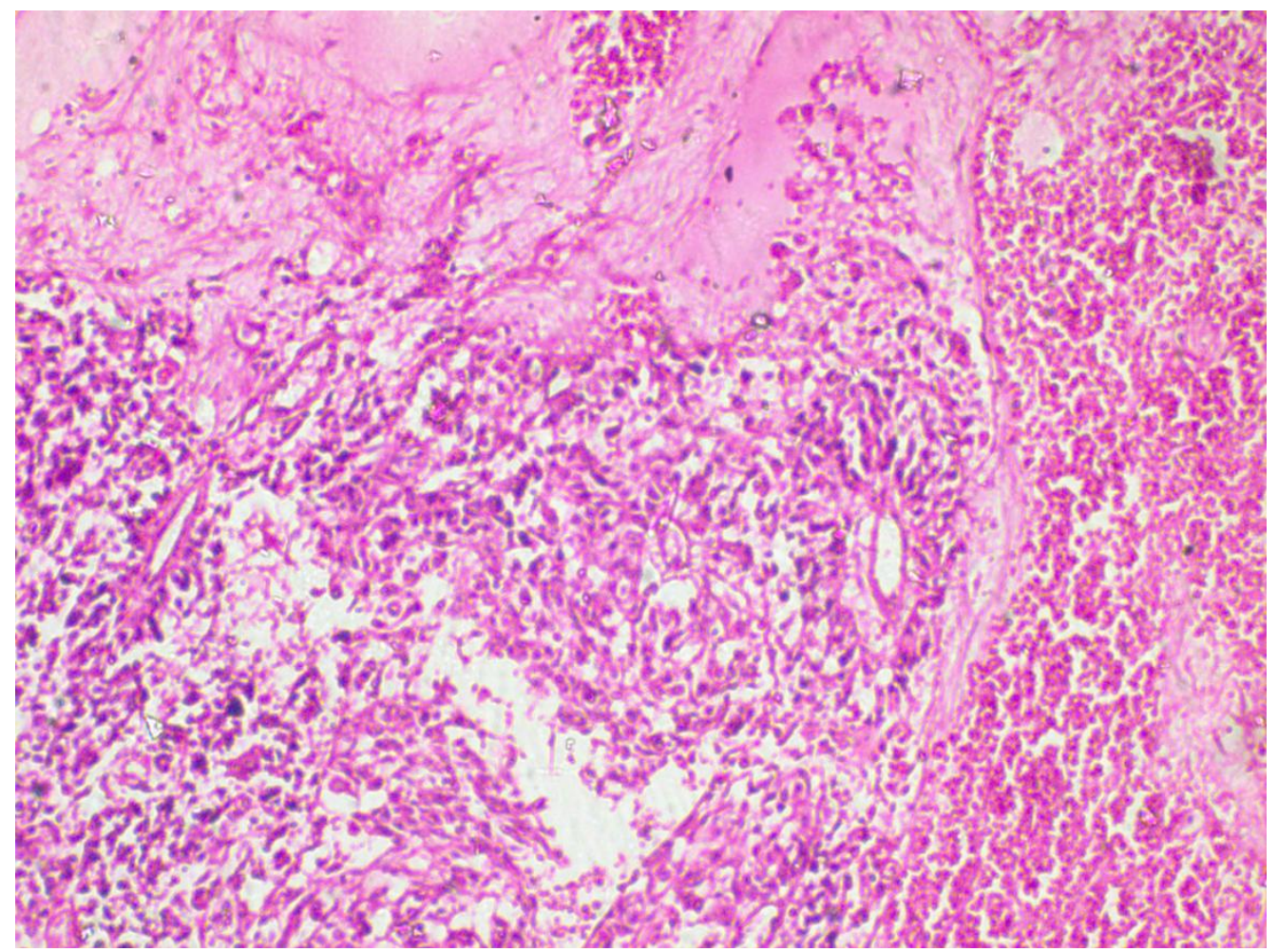

Fig.2: Section showing sheets and small nests of atypical cells separated by thick fibrocollagenous septae..These atypical cells are forming micropapillae and solid sheets and have moderate to marked pleomorphism and atypia.(H\&E,10x).

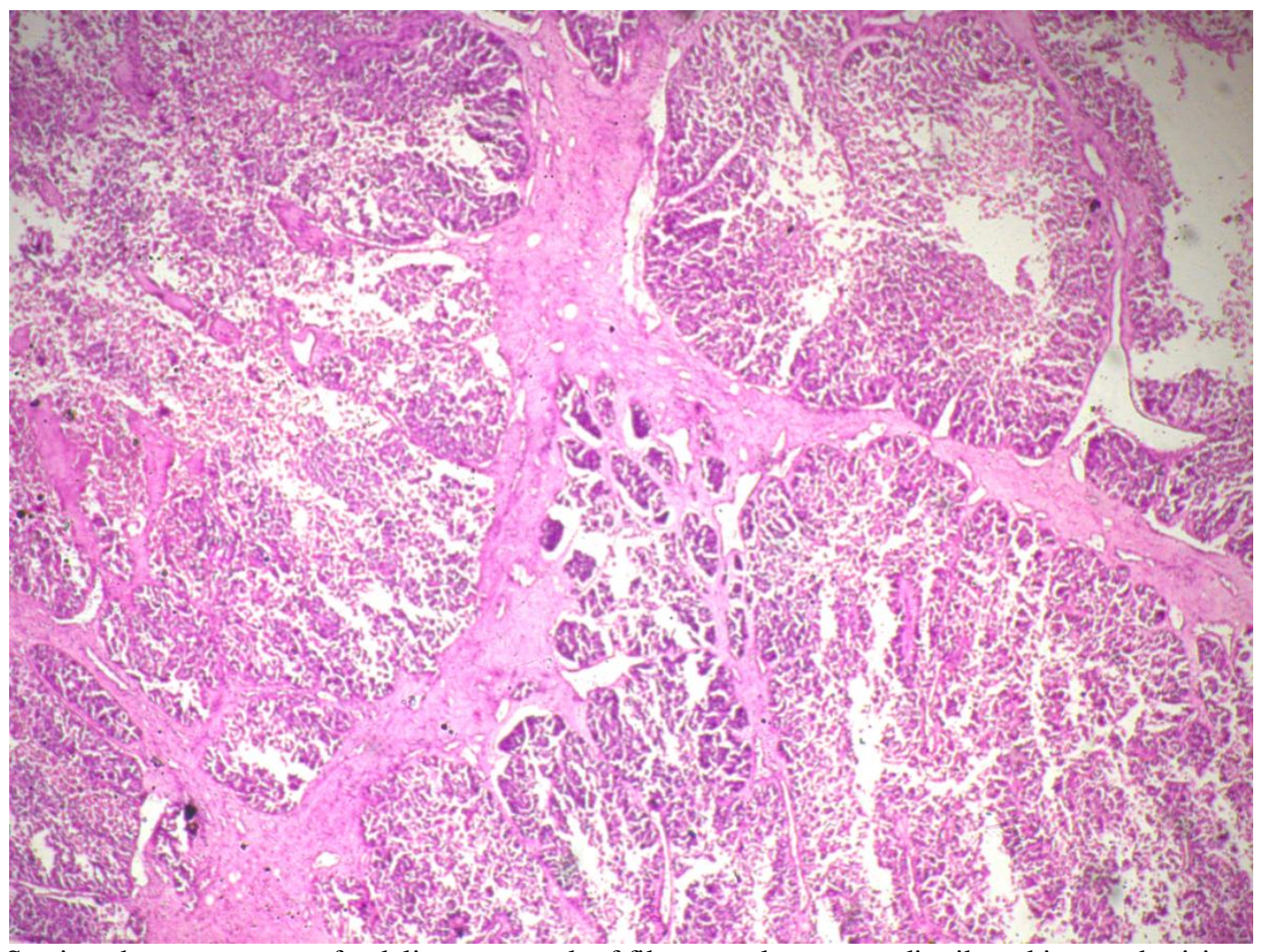

Fig.3: Section shows presence of a delicate network of fibrovascular stroma distributed in an arborising pattern throughout the compact sheets of malignant cells.(H\&E 40x). 
Apart from this florid ductal hyperplasia, lobular neoplasia, intracystic papillary carcinoma (IPC), and ordinary low-nuclear-grade ductal carcinoma in situ can be kept as a differential. Florid ductal hyperplasia has no fibrovascular core, palisading of cells or presence of mucin. Mitotic activity is not a feature of florid ductal hyperplasia(2,14). Lobular neoplasia is shows discohesion of cells and lacks papillary fronds.2. Immunohistochemistry using e- cadherin, shows positivity in SPC and it is negative in lobular proliferations. Intracystic papillary carcinoma is present in elderly patients. It is well circumscribed, and may lack a layer of myoepithelial cell layer at the periphery. Low grade DCIS does not have the morphology like that of SPC, or the cells with plasmacytoid or spindle cell appearance. The presence of mucin, branching fibrovascular stroma, and ducts encompassed by fibrosis are not features of DCIS $(2,14)$.

In the absence of invasion, SPCs have a better outcome. For the cases associated with invasion, prognosis will depend upon the invasive component of the tumor(14). In these cases, metastasis can occur without axillary lymph node involvement(1,14). Maluf and Koerner described a case in which lung metastasis occurred without the evidence of axillary lymph metastasis.

\section{Conclusion:-}

Solid papillary carcinoma is an unusual breast tumor. Invasive solid papillary carcinoma is a rare variant. Clinically and histologically they are distinct breast tumors that predominantly occur in elderly patients. For the cases showing invasion, prognosis depends on the invasive component.however cases without invasion show a better prognosis.

\section{References:-}

1. Maluf HM, Koerner FC. Solid papillary carcinoma of the breast: a form of intraductal carcinoma with endocrine differentiation frequently associated with mucinous carcinoma. Am J Surg Pathol. 1995;19(11):1237-1244.

2. Nassar H. Solid papillary carcinoma of the breast. Pathol Case Rev. 2009; 14(4):157-161.

3. Yamada M, Otsuki Y, Shimizu S, Tanioka F, Ogawa H, Kobayashi H.

4. Cytological study of 20 cases of solid-papillary carcinoma of the breast. Diagn Cytopathol. 2007;35(7):417422.

5. Elverici E, Barc NA, Tqrksoy ZO, Araz L, Yqksel E. Bilateral invasive papillary carcinoma Breast.Clinical Imaging. 2007;31:419-21.

6. Louwman MWJ, Vriezen M, Beek MWPMv, Nolthenius-Puylaert MCBJET, Sangen MJCvd, Roumen RM, et al. Uncommon breast tumors in perspective: Incidence, treatment and survival in the Netherlands.International Journal of Cancer. 2007;121(1):127-35.

7. Collins LC, Carlo VP, Hwang H, Barry TS, Gown AM, Schnitt SJ. Intracystic papillary carcinomas of the breast: a reevaluation using a panel of myoepithelial cell markers. Am J Surg Pathol. 2006;30(8):1002-1007.

8. Nassar H, Qureshi H, Volkanadsay N, Visscher D. Clinicopathologic analysis of solid papillary carcinoma of the breast and associated invasive carcinomas. Am J Surg Pathol. 2006;30(4):501-507.

9. Rosen PP, ed. Rosen's Breast Pathology. 3rd ed. Philadelphia, PA: LWW; 2009:433-437.

10. Nassar H, Qureshi H, Volkanadsay N, Visscher D. Clinicopathologic analysis of solid papillary carcinoma of the breast and associated invasive carcinomas. Am. J. Surg. Pathol. 2006;30:501-07.

11. Yoshimura N, Murakami S, Kaneko M, Sakatani A, Hirabayashi N, Takiyama W. Synchronous bilateral solid papillary carcinomas of the breast. Case Rep Surg. 2013;2013:812129.

12. Eremia IA, Ciobanu M, Tenea T, Comănescu MV, Crăiţoiu S. Invasive papillary carcinoma of the mammary gland: histopathologic and immunohistochemical aspects. Rom J Morphol Embryol. 2012;53:811-815.

13. Terzi A, Uner AH. An unusual case of invasive papillary carcinoma of the breast. Indian $\mathrm{J}$ Pathol Microbiol. 2012;55:543-545.

14. Bhosale SJ, Kshirsagar AY, Sulhyan SR, Jagtap SV, Nikam YP. Invasive Papillary Breast Carcinoma.Case Rep Oncol. 2010;3:410-415.

15. Kuroda N, Fujishima N, Inoue K, Ohara M, Mizuno K, Lee GH. Solid papillary carcinoma of the breast: imprint cytological and histological findings. Med Mol Morphol. 2010;43(1):48-52.

16. Nicolas MM, Wu Y, Middleton LP, Gilcrease MZ. Loss of myoepithelium is variable in solid papillary carcinoma of the breast. Histopathology. 2007;51: 657-665.

\section{Conflict of interest:}

There are no conflict of interests to disclose. 